\title{
Derrida, políticas de la sexualidad
}

Derrida, politics of sexuality

Domingo Fernández Agis*

recebido: 10/2014

aprovado: $12 / 2014$

\begin{abstract}
Resumen: Una serie de conceptos derridianos estarán presentes a lo largo de este escrito, pues en base a ellos he intentado construir cierto modelo de interpretación de las ideas de Derrida en torno a la sexualidad y sus implicaciones políticas, en el más amplio sentido del término. Forman parte de la mencionada serie los siguientes: escritura, performatividad y deconstrucción. Estas páginas no tienen ni pueden tener pretensión de exhaustividad al abordarse en ellas un asunto que un breve ensayo como éste jamás podría agotar. Planteo aqui que sobre estos conceptos es necesario basar la reflexión acerca de la sexualidad, tal y como Derrida la plantea, así como su relación con diversas políticas que afectan a la reproducción, el placer, la privacidad y la identidad.

Palabras clave: Derrida, sexualidad, política, escritura, placer, privacidad, identidad.
\end{abstract}

Abstract: A series of Derridean concepts will be present throughout this paper, because based on the way they've tried to build model interpretation of Derrida's ideas about sexuality and its political implications. They are part of that series the following: writing, deconstruction and performativity. These pages have no claim to completeness can be addressed to them a matter that a short essay like this could ever finish off. I understand these concepts is necessary to base reflection about sexuality, as Derrida understands as well as its relationship to various policies affecting reproduction, pleasure, privacy and identity.

Keywords: Derrida, sexuality, politics, writing, pleasure, privacy, identity.

* Universidad de La Laguna. Facultad de Filosofía. Profesor Titular. Departamento de Historia y Filosofia de la Ciencia, la Educación y el Lenguaje.Em@il:dferagi@ull.edu.es

Problemata: R. Intern. Fil. v. 5. n. 2 (2014), p. 252-273 e-ISSN 2236-8612 doi:http://dx.doi.org/10.7443/problemata.v5i2.21155 


\section{Introducción}

Una serie de conceptos derridianos estarán presentes a lo largo de este escrito, pues en base a ellos he intentado construir cierto modelo de interpretación de las ideas de Derrida en torno a la sexualidad y sus implicaciones políticas. Forman parte de la mencionada serie los conceptos siguientes: escritura, performatividad y deconstrucción. De ellos me serviré en estas páginas, que no tienen ni pueden tener pretensión de exhaustividad al abordarse en ellas un asunto que un breve ensayo como éste jamás podría agotar.

Como decía, entiendo que sobre estos conceptos es necesario basar la reflexión acerca de la sexualidad, tal y como Derrida la plantea, así como su relación con diversas políticas que afectan a la reproducción, el placer, la privacidad y la identidad. Cada uno de esos conceptos ha de estar presente en los epígrafes que iré desarrollando a continuación, aunque no abordaré en estas páginas, insisto en ello, un desarrollo sistemático de las implicaciones particulares que tiene cada uno de ellos, más allá de analizar sus interacciones con el asunto que aquí nos ocupa: lo que he denominado políticas de la sexualidad, aludiendo no sólo a la obra de Derrida titulada Politicas de la amistad, sino sobre todo, a la doble dimensión que para nosotros poseen sus ideas y análisis relacionados con la sexualidad. Me refiero, por un lado, al trabajo que realiza de puesta al descubierto y denuncia de las distintas formas de discriminación y dominación sexual que aún persisten en el mundo occidental. Aludo, por otra parte, a las implicaciones que sus ideas sobre la sexualidad tienen, consideradas desde un punto de vista político. En todo caso, a través de la referencia a los aludidos conceptos intentaré profundizar en la exposición de diversas políticas de la sexualidad, atendiendo a las tendencias observables en la actualidad y de un modo específico. 


\section{Reproducir y reproducirse}

En la reproducción sexual subyace el deseo -consciente o no- de proyectar lo que somos hacia el futuro, de formar parte del futuro a través de la descendencia. La reproducción sexual produce la diferencia mientras mantiene la identidad y la proyecta en el tiempo. La inscripción biológica guarda una peculiar relación con la memoria y ésta, en el caso de los humanos, está vinculada asimismo a la escritura desde hace al menos diez milenios. Retomando y reinterpretando las referencias platónicas, la escritura ha sido analizada como phamakon por Derrida. Dejar escrito, dejar por escrito, es un objetivo que tiende a crear y prolongar. En definitiva, el deseo de reproducirse y perdurar impulsa la escritura.

Cuando analizamos la actividad reproductiva humana, advertimos que no es menos artificial que la escritura o bien, abordándolo desde el ángulo opuesto, que la actividad simbólica que está a la base de la escritura no es menos natural para nosotros que la reproducción sexual. En todo caso, la correlación entre ambas resulta iluminadora, pues no hay promesa de perdurabilidad que deje de pasar por ese doble registro.

\section{Gozar en el secreto}

El placer puede ser analizado como instrumento de subversión, pero de forma análoga, el placer puede funcionar como mecanismo de sumisión.

Ante esto, deberíamos preguntarnos por qué puede funcionar de ambas formas, en ambos sentidos. También habría que responder, al hilo de esas consideraciones a la pregunta acerca de si es el goce un derecho, tal y como se ha planteado en tantas ocasiones.

Ante éste último interrogante habría que decir, en primer lugar, que si pudiera entenderse el goce como un derecho, dejaría de desempeñar cualquier papel posible en aras de una ruptura con lo establecido y sería tan sólo un instrumento al servicio del encaje pleno de los individuos en el orden político vigente. Los derechos se ejercen dentro de un orden social y se establece de facto, a través de su ejercicio, una correspondencia 
entre derecho y orden. Se implican, mantienen y refuerzan entre sí, sin que tenga el menor sentido hablar de un derecho con funciones subversivas, puesto que éstas conllevarían la ruptura con el orden jurídico-político que garantiza el ejercicio de los derechos.

Sin embargo, por su carácter universal, los Derechos Humanos podrían ser entendidos como una excepción dentro del anterior esquema interpretativo. Entre otras cosas porque, en muchos contextos sociales y políticos, su defensa y ejercicio puede provocar efectos de innovación y de subversión del sistema vigente. En este sentido, cabría preguntar si puede entenderse el derecho al goce como un Derecho Humano y, si nos inclinamos a considerarlo así, por qué habría que levantar una frontera insalvable en este ámbito, evitando a toda costa la extensión de este derecho también a los animales (Derrida, 2006: 54 y ss.).

Por lo demás, Derrida expresa de diferentes forma a lo largo de su obra La carte postale la importancia de la mediación del secreto para alcanzar el goce. Para él, sólo cabría la posibilidad del goce en el secreto y a partir del secreto (Derrida, 1980: 7 y ss.). El secreto, la reserva de un espacio de intimidad, tanto individual como de los sujetos que se comprometen entre sí en la búsqueda del placer, es la condición primaria del goce. Sin secreto, con la visibilidad plena y la transparencia completa, los individuos no pueden explorar las posibilidades del placer.

Estamos rodeados de apelaciones a la identidad, de incitaciones a ser quienes somos, de denuncias implícitas de la alienación que padecemos, de invitaciones más o menos explícitas a superarla. Sin embargo habría que tener en cuenta la existencia de muy distintas formas de concebir la identidad. Para nuestros objetivos aquí, existen tres que tienen una particular relevancia. Me refiero a la identidad como construcción por parte del poder, a la identidad entendida como reconstrucción y espacio de resistencia y a la identidad interpretada como juego y libertad. Las dos primeras directrices nos remiten a las conexiones entre Foucault y Derrida. Por lo que respecta a la tercera, hay que decir que la relación entre Lacan y Derrida muestra a través de ella una pertinencia particular. 


\section{Política y sexualidad}

¿Es posible la política al margen de la sexualidad? No aludo a la dificultad de abstraerse de los escándalos producidos por el cruce indiscreto de ambas, sino a la política y el sexo como elementos clave y definitorios de la comunidad humana. Desde el momento en que consideramos la naturaleza performativa de la definición sexual, comprendemos que política y sexo sólo pueden separarse mediante un ejercicio convencional que imponga su singular violencia sobre ambas.

Por otra parte, aunque se pretenda lo contrario, la política hoy es ante todo biopolítica y está impregnada de sexualidad.

En la entrevista que lleva por título, "'Il faut bien manger' ou le calcul du sujet", que data de 1989, encontramos una sugerente cita que hace Jean Luc Nancy. Éste, al preguntar a Derrida, recuerda que, para Hegel, "el sujeto es lo que puede retener en sí mismo la contradicción” (Derrida, 1992: 276).

En relación con esto, sería conveniente, a mi parecer, reflexionar a partir de la consideración de la realidad como vibración de lo imposible. Podemos considerar, en efecto, que la realidad es producto de una vibración en lo imposible, antes que ser fruto de una oscilación entre lo posible y lo imposible. De hecho, tal como nos ha mostrado Derrida, no puede definirse partiendo de una transacción entre lo posible y lo materializable, pues siempre quedaría un resto indefinible e inabarcable.

Pero, como bien sabemos, las narrativas de la sexualidad se entrecruza continuamente con la historia de las distintas formas de expresión simbólica. Habría que hacer, en particular, una referencia atenta a su entrecruzamiento con la historia del nombrar. Derrida señala al respecto que

este trazo estructural y general se encuentra enraizado en una cierta historia, como oportunidad de la filiación, del nombre heredado, de tal forma que la renombrada (y Montaigne habla tanto del nombre propio como del renombre que lleva este nombre legendario al conocimiento del amigo por venir y hace así nacer la amistad). Sobre las dos formas de este enraizamiento (herencia del nombre y renombre social) esta historia deja menos oportunidades a la mujer, a la hija, a la hermana. No queremos decir, ninguna oportunidad: decimos menos oportunidades. Cuando se habla de hegemonía, es decir, de relación de fuerzas, las leyes de 
estructura son tendenciales, no (se) determinan en términos de sí o no, por consiguiente, de exclusión pura y simple, sino de diferencia de fuerza, de más o de menos" (DERRIDA, 1994: 325).

No hay amor sin amistad y tampoco puede darse sin ella la complicidad necesaria para una sexualidad plena (Marion, 2003: 143). Por eso, una pregunta pertinente aquí se refiere al orden social cuya construcción es imposible sin que exista cierta amistad difusa en el tejido social: la democracia.

Si se quiere retraducir este elemento en hipótesis o en pregunta, estas tomarían quizá entonces, para concluir provisionalmente aquí, la forma siguiente: ¿es posible pensar poner en pie la democracia, lo que conservaría aún el viejo nombre de democracia, desenraizando en ella todas las figuras que la amistad (filosófica y religiosa) prescriben en ella de fraternidad, a saber de familia o de etnia androcéntrica? ¿Es posible, asumiendo una cierta memoria fiel de la razón democrática o, simplemente, de la razón, diría incluso de las Luces, de una cierta Aufklärung (dejando así abierto el abismo que se abre aún hoy bajo estas palabras), no para fundamentar, allí donde no se trata sin duda de fundamentar, sino de abrir al porvenir, o más bien al 'ven' de una cierta democracia? (DERRIDA, 1994: 339).

Dos términos clave dan pleno sentido a la idea de acogida hospitalaria que es consustancial a la democracia: viens (ven) y reste (quédate). Sin hospitalidad la democracia deviene una ficción. Lo interesante ahora, a efectos del trabajo que aquí estamos abordando, es ver cómo las políticas de la sexualidad se relacionan con la democracia y, en particular, con la acogida. La invitación a venir y a permanecer junto a nosotros son piezas esenciales para articular políticas de la sexualidad que excluyen las biopolíticas sexuales marginalizadoras.

La democracia no es un sistema político logrado y cerrado al futuro, por el contrario, siempre está en proceso de construcción, siempre está "por venir".

Derrida plantea que

la democracia sigue estando por venir, es ahí donde radica su esencia en tanto que resto: no solamente

Problemata: R. Intern. Fil. v. 5. n. 2 (2014), p. 252-273 
permanecerá indefinidamente perfectible, por lo tanto, siempre insuficiente y futura, sino perteneciendo al tiempo de la promesa, quedará siempre, en cada uno de sus tiempos futuros, por venir: incluso cuando hay democracia, esta no existe nunca, no está nunca presente, permanece como el objeto de un concepto no presentable (DERRIDA, 1994: 339).

En Politiques de l'amitié, Derrida habla de la ausencia de la mujer en la Teoría del partisano de Carl Schmitt. Se pregunta por el significado de esa ausencia y concluye que esconde algo importante. Piensa que tal vez la mujer sea, para Schmitt y quienes piensan como él, el enemigo absoluto (DERRIDA, 1994: 181).

Cuando Derrida reflexiona acerca de las razones de la ausencia de la mujer en la teoría de Carl Schmitt, plantea dos posibles opciones, que trascienden con mucho el horizonte en el que Schmitt se movía, afectando de una manera general al modo en que concebimos hoy la política. Por una parte, se plantea si debemos considerar que la política es de hecho falocéntrica. Por otro lado, apunta la necesidad de analizar de una manera diferente el concepto de lo político y habla de la necesidad de inventar otros nombres y conceptos, para transcender esta forma de entender la política (DERRIDA, 1994: 183).

\section{Hymen e invaginación}

Estas consideraciones previas nos permiten desembarcar en el comentario del contenido de "Chorégraphies», texto que recoge el resultado del intercambio de cartas que Derrida mantuvo con Christie V. McDonald, en 1982. Ella le planteaba en una de esas misivas que en sus trabajos Derrida ponía de relieve la forma en que la mujer ha cuestionado, cuando lo ha hecho, su subordinación con respecto al hombre. Le recordaba cómo, en Positions, hablaba de la existencia de dos fases de la deconstrucción en relación a lo que hemos llamado aquí políticas de la sexualidad. En la primera se produciría una inversión de las funciones respectivas de los términos hombre y mujer. Esto prepararía la segunda fase, la más radical del proceso deconstructivo, que abocaría en la redefinición del concepto considerado. Pero, como Christie V. McDonald ponía 
de manifiesto, la différance nos pone en contacto con toda una serie de conceptos que tienen connotaciones sexuales, en particular hymen (DERRIDA, 1972) e invaginación (DERRIDA, 1986).

Para ella, el término hymen conlleva un marcado semántico particularmente interesante, pues se entrecruzan en él dos significaciones que aluden, respectivamente, a la membrana que se encuentra en el órgano femenino y al matrimonio. En la primera acepción alude a lo que protege la virginidad de la mujer, mientras que en la segunda se refiere a la consumación del acto sexual (DERRIDA, 1972: 240 y ss.).

Mientras que el juego importante sobre las etimologías (en las que motivaciones inconscientes se manifiestan a través de las transformaciones y excesos históricos de uso) efectúa, según parece, un desplazamiento de estos términos, y provoca también un problema para aquellos que buscarían definir lo que es específicamente femenino. Eso no se debe tanto al hecho de que estos términos son $\mathrm{o}$ bien infravalorados $\mathrm{o}$ bien sobreevaluados, como partes del cuerpo de la mujer. Se debe más bien al hecho de que en la economía de un movimiento de escritura que siempre resulta evasivo, no se puede decir jamás con precisión si el término en cuestión implica una complicidad o una ruptura con la ideología del momento (...). Desde esta perspectiva, una nota de la página 201 de «La double séance» me viene a la mente, referida a la escritura, su transformación y su generalización. El ejemplo citado es el de un cirujano que, conociendo las dificultades de Freud para admitir la posibilidad de la histeria masculina, exclama: 'Pero, mi querido colega, ¿cómo puede usted decir cosas tan absurdas? Hysteron quiere decir útero, ¿cómo podría, entonces, ser histérico un hombre?' ¿Cómo podemos cambiar la representación de la mujer? ¿Podemos alejarnos de la orilla, de allí donde la mujer es esposa (ésta 'será nombrada mujer (icha) porque ha sido tomada por un hombre (ich)', Gen. 2, 23) para ir al vientre donde ella es madre ('el hombre ha nacido de la mujer', Job 14, 13), sin una pérdida esencial? (DERRIDA, 1992a: 103-107).

En efecto, el peso del lenguaje es mayor de lo que sospecha. La respuesta de Jacques Derrida a las cuestiones que 
planteaba su interlocutora en el pasaje que acabamos de leer es la siguiente:

cuando se determina la diferencia sexual en oposición al sentido dialéctico, según el movimiento hegeliano de la dialéctica especulativa cuya necesidad permanece tan potente mucho más allá del texto de Hegel, parece desencadenarse la guerra de sexos; pero se precipita el fin de la misma por la victoria del sexo masculino. La determinación de la diferencia en oposición está destinada, en realidad, a borrar la diferencia sexual. La oposición dialéctica neutraliza o 'sustituye' la diferencia. Pero cada vez, según una operación subrepticia que es preciso hacer desentrañar, se asegura el dominio falocéntrico bajo la cobertura de la neutralización. Estas paradojas son ahora mejor conocidas. Y este falocentrismo se apoya a veces, aquí y allá, en un apéndice: cierto feminismo. Incluso falocentrismo y homosexualidad pueden llegar a darse, si puede decirse así, en pareja, y entiendo estos vocablos en un sentido muy amplio y radical, ya se trate de homosexualidad femenina o masculina. ¿Y si 'la esposa' o 'la madre' -que usted parece segura de poder disociar- fueran todavía figuras de esta dialéctica homosexual? Me refiero ahora a su pregunta sobre la 'representación' de la mujer y sobre tal 'pérdida' en el pasaje desde el lugar del hombre a la vagina de la mujer, de la esposa, dice usted, a la madre. ¿Por qué habría que escoger, y solamente entre estas dos posibilidades, estos dos 'lugares', suponiendo todavía que se pueda verdaderamente disociarlos? (DERRIDA, 1992a: 1037).

A continuación, Derrida se extiende en la explicación del significado de dos conceptos que tienen para él una importancia central: hymen e invaginación. Para él, tales términos

no designan solamente figuras del cuerpo femenino. Se presupone incluso la existencia de un saber seguro sobre qué es un cuerpo femenino o masculino y se presupone también que la anatomía constituye aquí el último recurso. Lo que permanece indecidible no concierne tan sólo a la línea de separación entre los dos sexos. Como usted lo ha recordado, este movimiento no revierte finalmente ni a las palabras ni a los conceptos, y lo que queda de lenguaje ahí dentro no se deja abstraer de la performatividad (marcante, marcada) que nos compromete aquí, de entrada, por los ejemplos que

Problemata: R. Intern. Fil. v. 5. n. 2 (2014), p. 252-273 e-ISSN 2236-8612 
usted ha escogido, por los textos de Mallarmé o de Blanchot, por el trabajo de lectura o de escritura que los ha denominado y que ellos han denominado a su vez. Se podría decir, con todo rigor, que el hymen no existe. Todo lo que construye el valor de existencia es ajeno al 'hymen'. Y si hubiera hymen, no digo si el hymen existiera, el valor de propiedad no le conviene de entrada ni le convendría de antemano, por razones sobre las que he insistido en textos a los que usted ha hecho referencia. ¿Cómo se podría entonces atribuir propiamente a la mujer la existencia del hymen? (...) Diría otro tanto de la 'invaginación' (DERRIDA, 1992a: 112).

La cuestión implícita aquí es si no sería el hymen algo, en rigor, tan masculino como femenino. Pues, trascendiendo lo puramente histológico, el hymen es un hecho, más que una membrana localizada en una parte del cuerpo femenino, es algo ubicuo en la relación hombre-mujer, en la relación hombrehombre, en la relación mujer-mujer, en lugar de ser algo propio de la individualidad femenina.

Abundando en estas ideas, dice algo más adelante: "Y después de todo, incluso en la representación corriente, ¿por qué la vagina sería únicamente maternal? No sé, desde luego, si será preciso confiar en que se produzca en el futuro un cambio de representación" (DERRIDA, 1992a: 112).

Añadiendo después una referencia a la diferenciación sexual. En efecto, se refiere al número de los sexos, a la tiranía que el número 2 ejerce en este ámbito. En este sentido, entiende que

no es imposible que el deseo de una sexualidad innumerable venga aún a protegernos, como un sueño, contra un implacable destino que destella perpetuamente desde la cifra 2 . Y este cierre temible vendría a detener el deseo en el muro de la oposición. Podríamos debatir intensamente, pero no habría más que dos sexos, ni uno más ni uno menos. La tragedia tendría este gusto bastante contingente en suma, que haría falta afirmar, aprender a amar, en lugar de soñar lo innumerable. Sí, es posible, ¿por qué no? Pero ¿de dónde vendría entonces el 'sueño' de lo innumerable, si es un sueño? ¿Por sí sólo no queda probado aquello que sueña y que debe estar ahí para hacer soñar? Por lo demás, le pregunto qué sería la danza, ¿existiría si no

Problemata: R. Intern. Fil. v. 5. n. 2 (2014), p. 252-273 
cambiásemos en ella los sexos en número indeterminado, y la ley de los sexos, en ritmos muy variables? En un sentido en efecto riguroso, el cambio por sí mismo, a decir verdad, no sería suficiente, puesto que permanece el deseo de escapar a la única combinatoria y de inventar coreografías incalculables" (DERRIDA, 1992a: 115).

La trascendencia que estas reflexiones tienen en diversos espacios de discusión es indudable. En ese sentido, viene al caso recordar que, en una carta que escribe a Derrida fechada en 1969 Deguy afirma que va a releer "L'hymen". Sostiene que el análisis recogido en dicho texto es muy fuerte, lo denomina de hecho "dislocante", pues acaba provocando la diseminación del texto de Mallarmé y la "re-inseminación" de su lectura (DEGUY, 1969).

\section{Sexo y memoria}

En una entrevista que concedió a Anne Berger, realizada el 1 de diciembre de 1983, sostiene Derrida:

Sin embargo, si había una experiencia de la pérdida en el corazón de todo esto, la única pérdida de la que quedaría siempre inconsolable y que sería semejante a cualquier otra, la llamaría pérdida de memoria. El sufrimiento que está en el origen de la escritura para mí, es el sufrimiento de la pérdida de la memoria, no solamente del olvido o de la amnesia, sino del borrarse las huellas. De otro modo, no tendría necesidad de escribir, mi escritura no es, en primer lugar, una escritura filosófica o una escritura de artista, incluso si, en ciertos casos, puede tener el aire o tomar el relevo; mi deseo primario no es hacer una obra filosófica o una obra de arte, sino preservar la memoria (DERRIDA, 1992b: 153).

Preservar la memoria es conservar la identidad, tanto desde una perspectiva individual como colectiva. Pero, lejos de ser la memoria un fiel reflejo de lo sucedido, es el resultado de procesos de reconstrucción e idealización. No hay recuperación del recuerdo que no conlleve una reconstrucción idealizadora, salvo en el caso excepcional y cuasi patológico de la memoria eidética. Aun así, tras todo registro hay una voluntad de

Problemata: R. Intern. Fil. v. 5. n. 2 (2014), p. 252-273 e-ISSN 2236-8612 
reiteración. También sucede así en la actividad sexual, pues lo que Foucault denominaba el dispositivo de la sexualidad es en realidad una máquina de reiteración (MAGGIORI, 2014: 63-4). En ese sentido, sexo y filosofía tienen una singular relación.

\begin{abstract}
Lo que me gusta en los filósofos, lo que me interesa en ellos más que en otros finalmente, es que intentan construir las máquinas más económicas para reiterar. Se sitúan en ese punto del discurso en el que se posee el mayor control sobre el mismo, sobre el discurso como acto de memoria, de toda memoria en principio, lo que permite formalizar de forma económica el máximo de cosas que pueden decirse y pensarse. En este sentido, para mí, el filósofo es ante todo un guardián de la memoria; alguien que se pregunta sobre la verdad, sobre el ser, sobre el lenguaje, para conservar, entre la verdad y la custodia; seguro que has leído esos textos de Heidegger: la verdad es la custodia (DERRIDA, 1992b: 154).
\end{abstract}

La escritura es un recurso para mantener la memoria, para guardar para uno mismo algo que se quiere a toda costa conservar. Pero también es una ocasión para la entrega al otro, para abrirnos a la confianza en el otro. Hay cosas que no podemos guardar para nosotros, que no podemos guardarnos. Tienen que ser confiadas a otro, pues si no son confiadas a otro producirían un daño en quien no confía. Derrida habla de "la muerte, el envenenamiento, la intoxicación, la inflamación" y nos recuerda que "guardar quiere decir dar, confiar al otro" (DERRIDA, 1992b: 159).

La filosofía afianza la memoria a través de la construcción de dispositivos que permiten reconstruir cada elemento del sistema, siempre que sea necesario hacerlo. Hay así la posibilidad de producir una reiteración indefinida. Puede establecerse una analogía entre la filosofía -concebida desde la perspectiva de la construcción de un sistema de pensamiento- $\mathrm{y}$ la actividad sexual entre quienes tienen relaciones sexuales de forma habitual. Esto es así porque ellos conocen los mecanismos para producir la reiteración del placer. Pero el sistema, que produce de manera eficiente la reiteración e intenta ofrecer un refugio seguro en medio de una realidad llena de contingencias, no puede evitar que en determinados momentos nos veamos 
confrontados al riesgo y la violencia de la elección (GIDDENS, 1992: 42).

Es a partir del momento en que uno se rinde a la necesidad de la divisibilidad y de lo indecidible cuando la cuestión puede plantearse; y saber qué significan decidir, afirmar, es decir, también decidirse; una decisión que se tomara de otro modo que no fuera al borde de este indecidible, no sería una decisión. Por tanto, la decisión más grave, la Apuesta, el Sacrificio de Isaac, las grandes decisiones que es preciso tomar y que es preciso afirmar, se toman y son afirmadas en esta relación a lo indecidible mismo; en el momento mismo en que no son posibles, se convierten en posibles. Estas son las únicas decisiones posibles: las imposibles. Piensa aquí en Kierkegaard. La única decisión posible, es la decisión imposible. Es cuando no es posible saber, cuando es necesario hacerlo, cuando el saber no es determinante y no tiene ser, cuando una decisión es posible como tal. De otra forma, la decisión es una aplicación; se sabe lo que hay que hacer, está claro, no hay decisión posible; hay ahí un efecto, una aplicación, una programación (DERRIDA, 1992b: 157).

\section{Lo animal y lo humano en relación a la sexualidad}

En Points de suspension, se recoge también la entrevista realizada por Jean-Luc Nancy y que, bajo el título de "'Il faut bien manger' ou le calcul du sujet", fue publicada inicialmente en Cahiers Confrontation, en 1989. Es interesante rastrear las referencias que hace en esa entrevista a la reducción del animal a la condición de objeto. Con ello tendríamos un sugerente punto de partida para referirnos a la utilización del animal como objeto sexual, al tiempo que podríamos considerar también su reducción a producto alimentario para los humanos. En todo caso (COLLIN, 2014:145 y ss.), afirma allí Derrida que

sobre el discurso de Foucault, habría cosas diferenciadas que decir, según los momentos de su desarrollo. Se trata, quizá, de la historia de la subjetividad que, a pesar de ciertas declaraciones intensas sobre el difuminarse de la figura del hombre, no ha consistido ciertamente en 'liquidar' El Sujeto. Y en su última fase, se produce todavía el regreso de la moral y de un cierto sujeto ético. Para estos tres 
discursos (Lacan, Althusser, Foucault), para ciertos pensamientos que privilegian (Freud, Marx, Nietzsche), el sujeto puede ser interrogado, resituado, reinscrito, pero no resulta 'liquidado'. La cuestión '¿quién?', claramente en Nietzsche, insiste en ella con más fuerza aún. Esto es también verdad en Heidegger, referencia o determinación de la doxa de la que hablamos. El cuestionamiento ontológico que aborda subjectum en sus formas cartesiana y post-cartesiana es cualquier cosa menos una liquidación (DERRIDA, 1992c: 271).

A continuación, Jean-Luc Nancy le hace ver lo que el planteamiento de Heidegger implica como búsqueda de una salida a la "metafísica de la subjetividad". Apreciación a la que Derrida responde remarcando que no se trata de una salida y mucho menos de una liquidación (DERRIDA, 1992c: 271). Añade además que

\begin{abstract}
hay otra posibilidad, que me interesaría más en este punto: ella desborda la cuestión misma, la reinscribe en la experiencia de una 'afirmación', de un 'sí' o de un 'en-gage' (esta es la palabra de la que me sirvo en $D e$ l'esprit para describir la Zusage, este consentimiento al lenguaje, a la huella, que supone la pregunta más originaria ), este 'sí, sí' que responde antes mismo de poder formular una pregunta, que es responsable sin autonomía, ante y en vista de toda autonomía posible en este campo, etc. La relación consigo mismo no puede ser, en esta situación, otra cosa que différance, es decir, alteridad o huella (DERRIDA, 1992c: 275).
\end{abstract}

Y concluye que esto "no quiere decir que sea inhumana o sin sujeto, sino que es a partir de esta afirmación dislocada (por tanto sin 'firmeza' ni 'cierre') que algo como el sujeto, el hombre o lo que sea, puede tomar figura" (DERRIDA, 1992c: 276).

En el pensamiento contemporáneo, la disyunción entre lo animal y lo humano no ha hecho otra cosa que radicalizarse. Derrida se plantea, a partir de esa constatación, cómo afrontar la reducción del animal a la condición de objeto.

Nunca la distinción entre el animal (que no tiene o no es Dasein) y el hombre ha sido tan radical ni rigurosa en la tradición filosófica occidental, como con Heidegger. El animal no será jamás ni sujeto ni Dasein. No tiene

Problemata: R. Intern. Fil. v. 5. n. 2 (2014), p. 252-273 
inconsciente (Freud) ni relación al otro como otro, además no hay rostro animal (Lévinas). Es a partir del Dasein como Heidegger determina la humanidad del hombre (DERRIDA, 1992c: 283).

Apoyándose en la radicalidad de tal disyunción, el ser humano elude toda responsabilidad en relación al animal. Derrida adopta al respecto un punto de vista marcado por el pesimismo. Claro y contundente señala:

¿Se tiene una responsabilidad en relación a lo viviente
en general? La respuesta es siempre no, y la cuestión es
formulada, planteada de tal forma que la respuesta sea
necesariamente no en todo el discurso canonizado o
hegemónico de las metafísicas o las religiones
occidentales, incluso en las formas más originales que
pueda adoptar hoy, por ejemplo, en Heidegger o
Lévinas (DERRIDA, 1992c: 292).

En este sentido, Derrida habla de discurso "sacrificial", concretamente de "estructura sacrificial", refiriéndose mediante esa expresión a la inserción del discurso sobre el animal y acerca de lo viviente en general, en un tipo de "cultura" que defiende la muerte "no criminal" y específica del animal. Esto se concreta en la "ingesta, incorporación o introyección del cadáver" (DERRIDA, 1992c: 292-3). Para él, se trata de "una operación real y a la vez simbólica cuando el cadáver es animal". Mientras que es una operación meramente simbólica cuando el cadáver es humano (DERRIDA, 1992c: 293). En este sentido, quizá lo más llamativo sea que se reconozca la presencia del elemento simbólico allí donde parecía dominar la mera objetualidad.

Me gustaría demostrar algún día que este esquema implica la virilidad carnívora. Yo hablaría de un carnofalocentrismo si esto no fuese una especie de tautología o más bien de hetero-tautología como síntesis a priori, ... podrías traducir 'idealismo especulativo', 'devenir sujeto de la sustancia', 'saber absoluto', pasando por el 'viernes santo especulativo': sería suficiente con tomar en serio la interiorización idealizadora del falo y la necesidad de su paso por la boca, ya se trate de palabras o de cosas, de frases, del pan o del vino de cada día, de la lengua, de los labios o del seno del otro (DERRIDA, 1992c: 294). 
Por otra parte, insiste en poner al descubierto la violencia implícita en nuestra relación con el otro, sea éste animal o humano. Afirma, en tal sentido, que "las culturas llamadas noantropofágicas practican la antropofagia simbólica y construyen incluso su socius más elevado, quizá la sublimidad de su moral, de su política y de su derecho, sobre esta antropofagia" (DERRIDA, 1992c: 296).

En este contexto, Derrida emplea el concepto de biopolítica y se pregunta, tras aludir a ese concepto cuál debe ser el papel del Estado "en la determinación y protección de un sujeto viviente" (DERRIDA, 1992c: 297).

\section{Amistad y amor}

En todo caso, se refiere a la problematicidad que encontramos al tratar el amor desde la interpretación aristotélica de la amistad. En efecto, Aristóteles distingue entre amistad ética (que considera como expresión de la virtud), amistad por interés y amistad por placer. Sin embargo, en la relación entre los amantes puede darse una mezcla de esas formas de amistad. Uno de ellos puede buscar el placer y otro el beneficio o la utilidad (DERRIDA, 1994: 231-2).

\footnotetext{
Eros es una 'hipérbole' de la philia. Rarefacción hiperbólica. Eros no se dirige nada más que a uno sólo (pros ena). Pero ese es también el caso de los grandes amigos, de aquellos de los que los poetas han cantado la amistad. Estos himnos a la amistad conciernen siempre a parejas. Nunca más de dos amigos (DERRIDA, 1994: 240).
}

Esto nos lleva de nuevo a pensar en la exaltación clásica de la homosexualidad masculina pero, aun huyendo de ese tópico, introduce otra vez en el discurso una buena cantidad de equívocos en lo que se refiere a la conexión entre amistad y amor que creíamos ya haber sorteado. Delimitar cada uno de esos frentes resulta una tarea espinosa, toda vez que "es imposible (...) ser sexualmente neutro" (DERRIDA, 1994: 241).

En todo caso, la discusión que se da a lo largo de Políticas de la amistad, a propósito de los diferentes sentidos que puede adquirir la frase, ' $\mathrm{O} \mathrm{Oh}$, amigos, no hay ningún

Problemata: R. Intern. Fil. v. 5. n. 2 (2014), p. 252-273 
amigo!", lleva a Derrida a plantear la posibilidad o no, de que exista un único amigo y la relación que esto tiene con el amor. Reitera que no se puede amar a muchos y se plantea si otro tanto sucede con la amistad. No podríamos tener un gran número de amigos, porque no podría haber entonces, entre nosotros y nuestros amigos, una relación estrecha e intensa. En lo que se refiere a la política, la cuestión subyacente es la posibilidad de un sistema político en el que la amistad sea extensible al mayor número posible de personas.

Ninguna de estas cuestiones aparece como resuelta, en su recorrido a través de Platón, Aristóteles, Agustín de Hipona, Montaigne, Nietzsche y Carl Schmitt. Todas ellas remiten a indagaciones que permanecen aún abiertas, que dan lugar a una interminable discusión. En cuanto a la toma en consideración del sexo, en términos políticos, Derrida ha dejado constancia de cómo la no referencia a la diferencia sexual indica habitualmente una preferencia por lo masculino.

Considera que el sexo es una determinación esencial de la persona e intenta mostrar cómo hay un cierto ocultamiento de este hecho, que funciona dentro de una estrategia cuya finalidad es la dominación de la mujer (DERRIDA, 1994: 243). Hay, por tanto, una verdadera necesidad de construir relaciones de amistad en las que el sexo no quede excluido o planteado como límite a partir del cual la relación de amistad entra en un proceso de disolución. En contrapartida, basándose en la Ética a Nicómaco, señala que no hay amistad posible entre el hombre y Dios, por la desproporción y la distancia que existe entre ambos (DERRIDA, 1994: 251).

Por lo demás, Derrida entiende que es suficiente con que el concepto mismo "de amistad perfecta sea contradictorio, para que alguien levante la voz y diga ' $\mathrm{OOh}$, mis amigos, no hay ningún amigo!"” (DERRIDA, 1994: 253). Esto es así cuando iluminamos la amistad por medio de la racionalidad, pero Derrida señala que no todo pensamiento ha de traducirse a la lógica del cogito. Podemos encontrar otra vía. En ese sentido, alude a la afinidad entre la reflexión sobre la amistad y la reflexión sobre la mortalidad (DERRIDA, 1994: 253). Con ello alude a la función transversal desempeñada por la finitud.

A continuación se plantea la relación entre el ideal de fraternidad, griego y cristiano, y las utopías revolucionarias que han postulado una transformación de la sociedad. Esto se 
traduce en un pensamiento que nos exige una responsabilidad con respecto al porvenir (DERRIDA, 1994: 262-3).

Por ello se refiere a las ideas expresadas por Kant, en "Principios metafísicos de la doctrina de la virtud", segunda parte de la Metafisica de las costumbres (KANT, 2005: 228 y ss.) donde éste habla de la amistad. Señala que Kant no hace alusión en él a la diferencia sexual ni a la mujer (DERRIDA, 1994: 283). Kant entiende la amistad como ideal regulativo. Para él supone amor y respeto. Nunca puede realizarse en plenitud, aunque es necesario buscarla sin descanso (DERRIDA, 1994: 284).

Kant desconfía de la ternura y del amor. Para él, según Derrida, demasiada ternura y amor conducen a la ruptura de los lazos sociales. Demasiada ternura conduce inevitablemente a la tensión (atracción/repulsión), provocando un afán de posesión que acaba en enfrentamientos y conduce al desorden. Así pues, la amistad podría conducir, en su exceso, a ese mal, pero es también el remedio contra ese mal. El "amor es el mal, puede traer el otro mal y el mal puede siempre venir de él, el mal radical del más grande amor. El mal, es el abandono: a sí mismo o al otro" (DERRIDA, 1994: 287-8).

Frente a esos peligros, Kant le habría dado, según Derrida, más importancia a la amistad entendida como fraternidad (DERRIDA, 1994: 291). Habla por eso del amigo de los seres humanos, que comparte una sensibilidad hacia todo lo que les sucede. Pero el filántropo no es exactamente igual que el amigo de los hombres, pues se contenta con amar a los hombres, sin sentir esa sensibilidad y comunidad estética, que corresponde a un rigor racional infinito, a una Idea. La idea de igualdad se plantea como fuerza orientadora, contiene en sí misma una exigencia, una obligación.

Sentimiento de obligación, sensibilidad hacia un deber social, deuda de gratitud para con la humanidad: todo esto lo relaciona Kant con la idea de igualdad (DERRIDA, 1994: 2912). Derrida identifica el cosmopolitismo con la idea de una "democracia universal" (DERRIDA, 1994: 292). Lo vincula asimismo con el ideal kantiano de la paz perpetua.

Derrida se pregunta por qué Kant no habrá hablado de otras relaciones de parentesco posibles y, en particular, por qué 
ha hablado de "hermano" y no de "hermana" (DERRIDA, 1994: 293).

Se refiere asimismo Derrida al gran servicio que presta el "esquema antropológico" de la familia que Kant emplea. Se pregunta por la relación que puede existir entre "la doble exclusión que se ve en todos los grandes discursos éticopolítico-filosóficos sobre la amistad, a saber, de una parte, la exclusión de la amistad entre las mujeres, y de otra parte, la exclusión de la amistad entre un hombre y una mujer" (DERRIDA, 1994: 310). Afirma que "esta doble exclusión de lo femenino en este paradigma filosófico conferiría por tanto a la amistad la figura esencial y esencialmente sublime de la homosexualidad viril" (DERRIDA, 1994: 310).

Cita a Nietzsche, refiriéndose a Así habló Zaratustra. En concreto al apartado "Del amigo" (NIETZSCHE, 1998: 98), donde Nietzsche repite tres veces: "la mujer no es todavía capaz de amistad" (DERRIDA, 1994: 313). Para Nietzsche, el amigo se pone a prueba con el amigo, cuando ataca al enemigo de éste; es decir, en la guerra.

Por otra parte, el esclavo y el tirano no tendrían ni amigos ni enemigos, por no ser lo suficientemente libres e iguales. De ahí pasa Nietzsche a hablar de la mujer (NIETZSCHE, 1998: 96 y ss.), que para él es a la vez esclava y tirana (DERRIDA, 1994: 313-4). Por eso, la mujer sería incapaz de amistad y sólo conocería el amor (DERRIDA, 1994: 314).

Las tres alusiones de Nietzsche que Derrida analiza se refieren, respectivamente, al don, al superhombre y al espectro. El amigo del que habla Zaratustra es un amigo futuro, que aún está por llegar. A él, el filósofo le dona un mundo, le entrega las ideas necesarias para construir un nuevo mundo. Para Derrida, en ese sentido, "un amigo que no os dona el mundo, y un mundo que tiene forma y límite porque existe, porque es este mundo y no otro, no os dona nada. Para pensar esta amistad, que no sería ni griega ni cristiana, sería necesario pensar este don del mundo y sobre todo (pero sobre todo) de un mundo finito" (DERRIDA, 1994: 319). Derrida:

En un elocuente pasaje de Points de suspension, afirma

$$
\begin{aligned}
& \text { Creo que sin un movimiento de reapropiación narcisista, } \\
& \text { la relación con el otro sería absolutamente destruida, } \\
& \text { sería destruida de antemano. Es preciso que la relación } \\
& \text { con el otro ... - incluso si permanece siendo asimétrica, }
\end{aligned}
$$


abierta sin reapropiación posible- es preciso que esboce un movimiento de reapropiación en la imagen de símisma para que el amor sea posible, por ejemplo. El amor es narcisista (DERRIDA, 1992c: 212-3).

\section{Los elixires del amor}

En "Rhétorique de la drogue", señala atinadamente Derrida que "...el concepto de droga es un concepto no científico, instituido a partir de evaluaciones morales o políticas: lleva en sí mismo la norma o lo prohibido" (DERRIDA, 1992d: 222). Por tanto, remite a la ambigüedad con la que el ser humano afronta todo aquello que genera miedo. Por otra parte, aparece usualmente la droga presentada ideológicamente como un recurso artificial, opuesto a lo natural, siendo su consumo incompatible con la vida natural. Es pertinente, en ese sentido, recordar que, para Derrida, "el naturalismo no es más natural que el convencionalismo" (DERRIDA, 1992d: 244).

En todo caso, al abordar el tema hace referencia al Fedro de Platón. En concreto el pasaje en el que la escritura es presentada al rey como pharmakon. Éste responde que no es un pharmakon para la memoria, sino para la repetición. No es un verdadero remedio para la memoria, pues tan sólo ayuda a rememorar y repetir. Por su parte, Derrida considera la droga como un pharmakon, que permite la reiteración de un determinado estado mental. Habla asimismo de la escritura como droga y también se refiere a la escritura como juego (DERRIDA, 1992d: 247). Ambas cosas tienen una gran relevancia en relación a la sexualidad. A su vez, la escritura es también una conjura contra el miedo y un recurso para reconstruir el valor para enfrentarnos al mundo (MANRIQUE, 2014).

La alusión al miedo, por su parte, trae a la mente de cualquier persona recuerdos de infancia. El miedo siempre estaba ahí y no era posible esquivarlo. Salía a buscarte él mismo, sin esperar a que tú lo encontrases. Era el miedo a no tener y el miedo a tener; era el miedo al silencio y el terror ante las palabras; el miedo a la mentira y el miedo a la verdad. Todo eso se presentaba bajo el mismo caparazón, como si entraras en la coraza vacía de una tortuga muerta y vieras el adentro y el

Problemata: R. Intern. Fil. v. 5. n. 2 (2014), p. 252-273 
afuera, midiendo sin pensar las intensidades de la luz. Creías que cada una de las aberturas era una auténtica salida, pero luego resultaba ser una trampa mayor. Así, permanecer en el miedo te parecía la mejor forma de ponerte al abrigo de él. Porque había más miedo, una infinita cantidad de miedo, detrás de aquel que tú ya creías conocer. Me atrevería a decir que el miedo a la droga y los temores relacionados con la sexualidad, remiten a esa misma esfera de sensaciones que se remontan a la infancia. En ella, el valor se encontraba en una zona más o menos definida, entre el vacío de tus tripas y la sequedad de tu garganta. Por ella podías transitar tan sólo a ratos. No era un lugar en el que habitar. Apoyándote allí podías enfrentarte a lo que fuese, pero lo difícil era saber qué y cómo tenías que apoyar en esa zona de tu ser. Aficionado a la búsqueda de atajos, el ser humano ha ido encontrando distintos elixires con los que hacer frente a sus ancestrales temores, aliándose con la naturaleza o apoyándose en la química.

Los elixires del amor pretenden ser remedios contra el olvido de lo grato, contra la angustia, el dolor y el fracaso. A través de ellos se intenta reiterar y prolongar el placer, permitir al individuo disponer de un capital de valor que por sí mismo no atesora, que no le pertenece. En ese sentido hay una elocuente correlación entre filosofía, pharmakon y placer sexual.

\section{Bibliografía}

COLLIN, F. (2014), "Repenser l'éthique", en VVAA, L'Usage des plaisirs et le Souci de soi de Michel Foucault. Regards critiques 1984-1987. Caen: Presses universitaires de Caen, 2014.

DEGUY, M. (1969), Correspondance avec Derrida. IMEC Archives, Fonds DERRIDA, DRR 32.7.

DERRIDA, J. (2006), L'animal que donc je suis. Paris, Galilée. . (1980), La carte postale. Paris, Flammarion. . (1994), Politiques de l'amitié. Paris, Galilée. . (1986), Parages. Paris, Galilée.

(1972), «La double séance», en Derrida, J., La dissémination. Paris, Éditions du Seuil.

(1992a), «Chorégraphies». Correspondance avec

Christie V. McDonald parue dans Diacritics, 12 (2), été 1982, 
Johns Hopkins University Press. En, DERRIDA, J., Points de suspension. Paris, Galilée.

. (1992b), «Dialangues». Entretien avec Anne Berger. Paru dans Fruits, 1, décembre 1983, en DERRIDA, J., Points de suspension. Paris, Galilée.

. (1992c), " 'Il faut bien manger' ou le calcul du sujet ».

Entretien avec Jean-Luc Nancy paru dans Cahiers Confrontation, 20, hiver 1989, en DERRIDA, J., Points de suspension. Paris, Galilée.

. (1992d) "Rhétorique de la drogue", en DERRIDA, J., Points de suspension. Paris, Galilée.

GUIDDENS, A. (1992), La transformación de la intimidad. Madrid, Cátedra.

KANT, I. (2005), Metafísica de las costumbres. Madrid, Tecnos.

MAGGIORI, R. (2014), "Pourquoi le sexe est moral», en VVAA, L'Usage des plaisirs et le Souci de soi de Michel Foucault. Regards critiques 1984-1987. Caen, Presses Universitaires de Caen.

MANRIQUE, W. (2014), "Vargas Llosa y Le Clézio, dos nómadas que se cruzan en Segovia", "El país", 27 de septiembre.

MARION, J. -L. (2003), Le phénomene érotique. Paris, Grasset. 